\title{
Advances in the Remote Sensing of Terrestrial Evaporation
}

\author{
Matthew F. McCabe ${ }^{1, *}\left(\mathbb{C}\right.$, Diego G. Miralles ${ }^{2}\left(\mathbb{D}\right.$, Thomas R.H. Holmes ${ }^{3}\left(\mathbb{D}\right.$ and Joshua B. Fisher ${ }^{4}$ \\ 1 Water Desalination and Reuse Center, Division of Biological and Environmental Sciences and Engineering, \\ King Abdullah University of Science and Technology, Thuwal 23955-6900, Saudi Arabia \\ 2 Laboratory of Hydrology and Water Management, Ghent University, Coupure Links 653, \\ 9000 Ghent, Belgium; Diego.Miralles@UGent.be \\ 3 Hydrological Sciences Laboratory, NASA Goddard Space Flight Center, Greenbelt, MD 20771, USA; \\ thomas.r.holmes@nasa.gov \\ 4 Jet Propulsion Laboratory, California Institute of Technology, Pasadena, CA 91109, USA; \\ Joshua.B.Fisher@jpl.nasa.gov \\ * Correspondence: matthew.mccabe@kaust.edu.sa
}

Accepted: 10 May 2019; Published: 13 May 2019

\begin{abstract}
Characterizing the terrestrial carbon, water, and energy cycles depends strongly on a capacity to accurately reproduce the spatial and temporal dynamics of land surface evaporation. For this, and many other reasons, monitoring terrestrial evaporation across multiple space and time scales has been an area of focused research for a number of decades. Much of this activity has been supported by developments in satellite remote sensing, which have been leveraged to deliver new process insights, model development and methodological improvements. In this Special Issue, published contributions explored a range of research topics directed towards the enhanced estimation of terrestrial evaporation. Here we summarize these cutting-edge efforts and provide an overview of some of the state-of-the-art approaches for retrieving this key variable. Some perspectives on outstanding challenges, issues, and opportunities are also presented.
\end{abstract}

Keywords: evaporation; remote sensing; Earth observation; land surface modeling; land surface flux; CubeSats; high-resolution

\section{Introduction}

The exchange of water between the surface and the atmosphere plays a critical role in the complex dynamics driving the Earth's carbon, water, and energy cycles. As the only variable interlinking these system-level processes, the estimation of terrestrial evaporation (ET) has been a focus of sustained research for many decades [1,2]. While early process descriptions tended to focus on local scale estimation using available ground-based data, developments in satellite based remote sensing were exploited to produce some of the first large-scale evaporation products [3-5]. In more recent times, efforts describing terrestrial exchanges have culminated in multi-decadal and multi-resolution products that combine satellite and numerical weather prediction model output to span local, regional, and global scales [6-10].

While the various methodological approaches for flux estimation are relatively well developed [11-13], recent advances in Earth observation technologies [14], coupled with the exploitation of new retrieval and sensing techniques $[13,15]$, provide an opportunity for further insights into the evaporative process. We are in a "golden-age" of Earth-observation [14], with a wide variety of distributed sensing approaches and techniques available for routine Earth system characterization, providing data at unprecedented spatial and temporal detail. New types of satellite observations, such as solar induced 
chlorophyll fluorescence (SIF) $[16,17]$, together with advances in spatial and temporal resolution from CubeSats [18] or unmanned aerial vehicles [19], provide an opportunity to challenge both our process understanding and the models that we use to describe evaporative dynamics.

Indeed, a major driver of evolution in model descriptions is through confrontation with new data-sets. Unfortunately, this has not always been the practice, with scale-invariance an oft-implied modeling assumption. For instance, while evaporation models were often formulated for local scale application, they have routinely been extrapolated to regional and global scale application [12], with consequent issues of scaling and parameterization [20]. Likewise, improving our process understanding and representation is not purely a function of increasing the resolution of observations. Forcing scale-dependent modeling constructs with finer and finer spatio-temporal observations may not necessarily deliver new or deeper process insights. It is important that community progress in advancing process understanding, either through new modeling approaches or improved physical descriptions, keeps pace with (or even moves beyond) our capacity to observe the system. That is, model development efforts should aim to be transformational rather than iterative. Of course, a plateauing of model improvements is not necessarily problematic, especially if accurate results can be maintained when confronted by new observations. However, it would be naive to believe that the field of evaporation modeling (or "observation") has reached its nadir, and that there are no further improvements to be made.

As a consequence, there remain many opportunities for advancing our description, estimation and understanding of the terrestrial evaporation process. In a recent contribution, Fisher et al. [13] provided a motivational call to the community to address some of the science and application questions related to evaporation estimation. These included improvements in the accuracy of retrievals, spatio-temporal resolution, multi-scale coverage, and long-term monitoring, amongst many others. In light of such outstanding modeling and observational "challenges", this Special Issue sought to explore some of the technological and methodological advances that take the first steps towards developing new paradigms in evaporation estimation. The collection of contributions spans the exploration of both new and existing techniques, high-resolution (in space and time) approaches, as well as fundamental improvements in modeling descriptions and frameworks. The following sections provide an overview of the twelve manuscripts that comprise this Special Issue, together with some concluding thoughts and perspectives.

\section{Overview of Contributions}

\subsection{Innovative Techniques in Monitoring Evaporation}

Several articles in this Special Issue explored the potential of innovative techniques to map terrestrial evaporation, from local to global scales. Pagán et al. [21] investigate the use of satellite observations of solar-induced chlorophyll fluorescence to diagnose transpiration using data from the Global Ozone Monitoring Experiment 2 (GOME-2) and a variety of FLUXNET eddy-covariance sites. Results demonstrate that SIF data normalized by photosynthetic active radiation (PAR) are empirically related to the ratio of transpiration to potential evaporation. Overall, SIF/PAR dynamics capture the effect of phenological changes and environmental stress on transpiration, adequately reflecting the timing of this variability, especially during growing seasons. Moreover, the skill of state-of-the-art land surface models (LSMs) is also contrasted against eddy-covariance data and SIF/PAR retrievals, indicating deficiencies in the way models estimate transpiration and suggesting that SIF data can be used to constrain the formulations of transpiration via data assimilation.

Another innovative technique is presented by Vanella et al. [22], who focused on the estimation of evaporation during water stress and irrigated conditions using local meteorology and Sentinel 2 vegetation data. The authors adjust a dual crop coefficient FAO-56 approach using electrical resistivity tomography (ERT) data to monitor the soil wetting distribution patterns during and after irrigation phases. More precisely, ERT is used to accurately estimate the wet exposed fraction and therefore 
the water evaporated from the soil surface. Results indicate that differences in evaporation estimates relative to in situ eddy-covariance measurements can be substantially reduced with ERT. Moreover, the authors propose to empirically derive water stress factors by combining the eddy-covariance data and the ERT-adjusted FAO-56 evaporation estimates.

The study by Cheng and Kustas [23] applies the two-source energy balance (TSEB) model to thermal observations taken from an aircraft at a few meters resolution. While it is a clear example of the transition towards higher resolutions in evaporation remote sensing research that has been highlighted in this Special Issue (see Section 2.2), it also explores the innovative application of airborne thermal data. Results are compared to analogous evaporation estimates based on coarser scale ( $90 \mathrm{~m})$ data from the Advanced Spaceborne Thermal Emission and Reflection Radiometer (ASTER), and validated against data from a series of eddy-covariance towers. The evaporation data using aircraft observations shows satisfactory patterns and a higher accuracy than ASTER-based estimates when both are compared against flux tower measurements. In particular, the authors show that the high-resolution aircraft-based evaporation product is more suitable for heterogeneous terrains covering urban, agriculture, and natural vegetation, and suggest that TSEB can be used to accurately monitor the impact of urbanization on the surface energy balance using high resolution thermal observations.

\subsection{High-Resolution Remote Sensing Estimation: In Space and Time}

One of the critical outstanding questions in satellite remote sensing of ET is: What temporal resolution is required? There are trade-offs between temporal resolution, spatial resolution, and coverage from an engineering standpoint. Are these trade-offs linear, or are there inflection points whereby optimal compromises can be made? Guillevic et al. [24] investigated this question in depth using in situ eddy-covariance measurements from AmeriFlux sites. The authors evaluated the uncertainty in monthly averaged ET by removing data from the hourly/daily measurements. They found non-linearities where an optimal compromise was a four-day revisit scenario, which provided a significant improvement in ET estimation. The four-day scenario reduced uncertainty in ET by $40 \%$ relative to a 16-day revisit (e.g., Landsat). Moreover, they found that any return period greater than eight days was severely detrimental to ET estimation. Interestingly, they found no significant biases based on time of day-morning or afternoon. The authors clearly point out that these estimates vary quite a lot depending on land cover type or climate zone, so their numbers should be taken contextually to the objective of the reader.

Aragon et al. [25] examine the novel application of CubeSats to provide some of the highestresolution time-series estimates of crop water use ever retrieved from space. The authors introduce a modified version of the Priestley-Taylor Jet Propulsion Laboratory (PT-JPL) model that allows for the integration of CubeSat-based leaf area index (LAI). Biophysical parameters of the model are also adapted for the specific conditions of the study site. The approach is evaluated over an irrigated farmland operating in an arid environment, with model estimates compared against eddy-covariance data. Results indicate a 33\% relative root mean square error (RMSE), with some observed underestimation of the model attributed to a possible misrepresentation of the local soil moisture condition. The paper highlights the spatio-temporal benefit of CubeSats for improved water management, as well as the need for further model development in the face of increasingly high-resolution satellite-based observations.

By utilizing ground radar measurements, geostationary observations, and newly developed high-resolution datasets of soil moisture and vegetation optical depth, Martens et al. [26] apply the Global Land Evaporation Amsterdam Model (GLEAM) at $100 \mathrm{~m}$ spatial resolution over The Netherlands, Flanders, and western Germany for the period 2013-2017. Results show that root-zone soil moisture estimates from GLEAM compare well with in situ measurements, and terrestrial evaporation estimates are also highly correlated to in situ data from five eddy-covariance sites. High resolution retrievals are compared to the coarse resolution GLEAM v3.2b data, as well as to data from the Satellite Application Facility on Land Surface Analysis (LSA-SAF) [27], and reference grass evaporation based on Makkink's equation. As expected, GLEAM estimates at high resolution show great spatial detail, yet further 
algorithm developments are required to improve the accuracy at fine scales if applications under more complex terrains are intended in the future. Nonetheless, the extensive use of microwave-based observations in GLEAM allows the provision of data under all weather conditions, and represents a viable alternative to traditional visible and infrared models to retrieve evaporation at field scales.

Anderson et al. [28] demonstrates the application of a multi-scale energy balance algorithm to provide a region-specific analysis of consumptive water use associated with land use changes in the Sacramento-San Joaquin Delta region in California. The fusion approach combines ET map timeseries based on thermal observations with high spatial but low temporal resolution and with moderate resolution but frequent temporal coverage. The methodology provides an effective tool for policymakers and farmers to understand how land use conversion could impact consumptive use and demand.

\subsection{Model Developments and Improvement in the Remote Sensing of Evaporation}

Improving the representation of the evaporative process in our models, either through new physical descriptions or novel estimation approaches, is critical to advancing our understanding of this key hydrological variable. The Special Issue featured a number of contributions exploring this important aspect. Spectral Mixture Analysis (SMA) was applied by Sousa and Small [29] in a study of Landsat 8 spectral scenes over the Sacramento Valley. In this analysis they relate the radiometric surface temperature to subpixel fractions of substrate, vegetation, and dark spectral endmembers. Their proposed approach provides a physically-based conceptual framework for mapping ET that unifies two widely-used approaches by simultaneously mapping the effects of albedo and vegetation abundance on the surface temperature field. The SMA fractions are relatively insensitive to sensor spatial resolution, unlike spectral indices that currently often represent vegetation abundance in ET estimation. Because SMA uses the full reflectance spectrum it could also be integrated with planned global hyperspectral imagers.

Poon and Kinoshita [30] explored the impacts that wildfire might have on the hydrological cycle by examining pre- and post-fire evaporation, employing a combination of remote sensing data and a novel support vector machine (SVM) approach. The authors seek to address the challenge of providing evaporation estimates in the absence of ground-based observations: One of the major limitations of many models. Remote sensing-based input variables were used to predict ET via an ensemble of SVM. The SVM were trained against an operational surface energy balance model (SSEBop) that captured a geographically and temporally distinct fire-affected watershed. The approach illustrated the feasibility of using machine learning to develop an evaporation model based on available remote sensing data, and demonstrated that the model could be transferred to regions with similar characteristics to provide useful predictions.

We often think of ET as a singular contribution, when it is instead comprised of multiple components that include canopy transpiration, soil evaporation, and interception evaporation. All sources are differentially impacted by, and sensitive to, changes in climate and $\mathrm{CO}_{2}$. Global satellite remote sensing retrievals have advanced to the point that the contributing components can be delineated. Yet, no study has sought to examine the sensitivities of models such as PT-JPL, GLEAM, or the Penman-Monteith algorithm behind the official Moderate Resolution Imaging Spectroradiometer evaporation product (PM-MOD), to these components. Talsma et al. [31] address this lack to reveal that the models were quite sensitive to each of the ET sources (which naturally differed amongst the models), the sensitivity dissipated when aggregated to the accumulated total evaporation. Internally, each model managed to balance an over-reliance on one component with an under-reliance on another. Talsma et al. conclude that the accumulated evaporation estimates, especially among PT-JPL and GLEAM, were very accurate, even though the models disagreed on the contributions of the respective sources.

A number of papers in this Special Issue noted the advancements and high accuracy of remote sensing-based evaporation algorithms, particularly for sensitive ecosystems. Arguably nowhere are water resources more constrained than in dryland systems, where people and natural ecosystems 
compete for limited water availability. It is these regions where accurate estimation may be of utmost importance to determine water use and management amongst competing sectors. Moyano et al. [32] apply the PT-JPL model with dryland thermal modifications to the critical environment of the World Heritage Doñana region of Spain. They demonstrated that the remote sensing retrieval captured in situ measurements, providing confidence that the approach can be used for the ongoing management of these important ecosystems.

Kumar et al. [33] investigated the level of agreement in flux partitioning resulting from a suite of land surface models in the North American Land Data Assimilation System (NLDAS) configuration. The authors quantify the contributions of two key factors explaining inter-model disagreements to the uncertainty in total domain-wide ET: Contribution of the local partitioning; and regional distribution of ET. The results indicate that while the uncertainty in local partitioning dominates the inter-model spread in modeled soil evaporation, the inter-model differences in transpiration are dominated by the uncertainty in the distribution of ET over the Eastern U.S. and the local partitioning uncertainty in the Western U.S.

\section{Concluding Thoughts and Perspectives}

The monitoring and measurement of terrestrial evaporation remains a topic of considerable relevance to multi-disciplinary studies in hydrology, meteorology, and ecology, as well as the agricultural and plant sciences (to name just a few). As such, it has been an area of active investigation for decades, driven in large part by the many challenging research questions that remain unanswered. These include fundamental questions on the influence and impacts that climate changes will have on our coupled water, energy, and food systems [34,35]; the relationship between evaporation and land-atmosphere feedbacks, extremes, and other climate feedbacks [36]; to more applied aspects such as the effective management and optimization of our water resource systems [37] (see Fisher et al. [13] for further discussion on some of these outstanding research questions).

Developments in our capacity to observe the Earth system and its dynamics provide an opportunity for further insights and improved descriptions of the terrestrial evaporative process. In recent times, the European Space Agency (ESA) Sentinel platforms [38] have provided a needed upgrade to the series of National Aeronautics and Space Administration (NASA) satellites that have been the backbone of Earth observation research for the last decade and more. In parallel, emerging satellite platforms [14] and technologies such as CubeSats [18] and unmanned aerial vehicles (UAVs) [19], are delivering unprecedented spatio-temporal capabilities, and facilitating novel sensor-fusion approaches relevant to enhancing evaporation [39]. Other platforms such as the ECOSTRESS sensor [40], provide a source for monitoring diurnal temperature patterns at high-resolutions, offering important insights into plant response and behavior and the means to resolve sub-daily evaporation dynamics.

To a certain degree, the theoretical constructs upon which the majority of our evaporation models are based have remained largely unchanged since the middle of the last century. As a consequence, one may start to question whether foundational concepts (for example, Penman's "big-leaf assumption") remain relevant in the face of observational improvements (i.e.; if the capacity to observe individual leaves is routinely available). Of course, advances will not be driven solely by just increasing spatial and temporal resolutions. Certainly, one of the most important aspects required to advance the development of evaporation models is our representation of the vegetation components inherent in the partitioning between soil evaporation, interception, and transpiration: an aspect that will benefit not only from resolution improvements, but also new retrieval approaches [32,33,41]. Given the array of existing sensing systems that span the visible, near-infrared, thermal, and microwave spectral ranges, efforts to utilize the varied information to better characterize land surface influences (e.g., plant form and function) are likely to provide further knowledge gains [42-44]. Likewise, the exploitation of hyper-spectral observations to deliver specific information such as SIF [21] as well as other enhanced metrics of vegetation function and condition [39], are providing supplementary sources of data to better inform key process elements [45]. 
The idea of new observations spurring development and advances in physical representations is not new, but it is one that is increasingly relevant in evaporation studies. Observational improvements and model developments provide parallel (yet overlapping) pathways towards advancing our knowledge and understanding of the evaporation response, with many excellent examples comprising this Special Issue. Finally, another aspect that is likely to become increasingly important is the use of data-driven approaches, exemplified through the adoption of artificial intelligence and machine learning techniques [46-48]. Regardless of the path taken, it is clear that efforts towards advancing the understanding, description and interactions of terrestrial evaporation present numerous challenges and opportunities. Given the central role that this important topic plays in multi-disciplinary investigations, there is clear potential to undertake novel, innovative, and impactful research towards addressing these outstanding problems.

Author Contributions: All authors contributed equally to the development of this Editorial.

Funding: MFM was supported by the King Abdullah University of Science and Technology. DGM acknowledges support from the European Research Council (ERC) under grant agreement 715254 (DRY-2- DRY). JBF contributed to this work at the Jet Propulsion Laboratory, California Institute of Technology, under a contract with the National Aeronautics and Space Administration (NASA). California Institute of Technology. Government sponsorship acknowledged. JBF was supported in part by NASA programs: SUSMAP, INCA, IDS, and ECOSTRESS.

Acknowledgments: The Guest Editors would like to thank all of the authors who contributed their research to this Special Issue, and also the many reviewers who provided valuable feedback on the submitted manuscripts.

Conflicts of Interest: The authors declare no conflict of interest.

\section{References}

1. Kalma, J.D.; McVicar, T.R.; McCabe, M.F. Estimating land surface evaporation: A review of methods using remotely sensed surface temperature data. Surv. Geophys. 2008, 29, 421-469. [CrossRef]

2. Wang, K.; Dickinson, R.E. A review of global terrestrial evapotranspiration: Observation, modeling, climatology, and climatic variability. Rev. Geophys. 2012, 50, RG2005. [CrossRef]

3. Moran, M.S.; Jackson, R.D.; Raymond, L.H.; Gay, L.W.; Slater, P.N. Mapping surface energy balance components by combining Landsat Thematic Mapper and ground-based meteorological data. Remote Sens. Environ. 1989, 30, 77-87. [CrossRef]

4. Kustas, W.P.; Jackson, R.D.; Asrar, G. Estimating Surface Energy Balance from Remotely Sensed Data. In Theory and Applications of Optical Remote Sensing; Asrar, G., Ed.; John Wiley and Sons: New York, NY, USA, 1989; pp. 605-626.

5. Brutsaert, W.; Sugita, M. Regional surface fluxes from satellite-derived surface temperatures (AVHRR) and radiosonde profiles. Bound. Layer Meteorol. 1992, 58, 355-366. [CrossRef]

6. Zhang, Y.; Peña-Arancibia, J.L.; McVicar, T.R.; Chiew, F.H.S.; Vaze, J.; Liu, C.; Lu, X.; Zheng, H.; Wang, Y.; Liu, Y.Y.; et al. Multi-decadal trends in global terrestrial evapotranspiration and its components. Sci. Rep. 2016, 6, 19124. [CrossRef] [PubMed]

7. Miralles, D.G.; Holmes, T.R.H.; de Jeu, R.A.M.; Gash, J.H.; Meesters, A.G.C.A.; Dolman, A.J. Global land-surface evaporation estimated from satellite-based observations. Hydrol. Earth Syst. Sci. 2011, 15, 453-469. [CrossRef]

8. Jung, M.; Reichstein, M.; Margolis, H.A.; Cescatti, A.; Richardson, A.D.; Arain, M.A.; Arneth, A.; Bernhofer, C.; Bonal, D.; Chen, J.; et al. Global patterns of land-atmosphere fluxes of carbon dioxide, latent heat, and sensible heat derived from eddy covariance, satellite, and meteorological observations. J. Geophys. Res. Biogeosci. 2011, 116, G00J07. [CrossRef]

9. Mu, Q.; Zhao, M.; Running, S.W. Improvements to a MODIS global terrestrial evapotranspiration algorithm. Remote Sens. Environ. 2011, 115, 1781-1800. [CrossRef]

10. Ryu, Y.; Baldocchi, D.D.; Kobayashi, H.; van Ingen, C.; Li, J.; Black, T.A.; Beringer, J.; van Gorsel, E.; Knohl, A.; Law, B.E.; et al. Integration of MODIS land and atmosphere products with a coupled-process model to estimate gross primary productivity and evapotranspiration from $1 \mathrm{~km}$ to global scales. Glob. Biogeochem. Cycles 2011, 25. [CrossRef] 
11. Miralles, D.G.; Jiménez, C.; Jung, M.; Michel, D.; Ershadi, A.; McCabe, M.F.; Hirschi, M.; Martens, B.; Dolman, A.J.; Fisher, J.B.; et al. The WACMOS-ET project-Part 2: Evaluation of global terrestrial evaporation data sets. Hydrol. Earth Syst. Sci. 2016, 20, 823-842. [CrossRef]

12. McCabe, M.F.; Ershadi, A.; Jimenez, C.; Miralles, D.G.; Michel, D.; Wood, E.F. The GEWEX LandFlux project: Evaluation of model evaporation using tower-based and globally gridded forcing data. Geosci. Model Dev. 2016, 9, 283-305. [CrossRef]

13. Fisher, J.B.; Melton, F.; Middleton, E.; Hain, C.; Anderson, M.; Allen, R.; McCabe, M.F.; Hook, S.; Baldocchi, D.; Townsend, P.A.; et al. The future of evapotranspiration: Global requirements for ecosystem functioning, carbon and climate feedbacks, agricultural management, and water resources. Water Resour. Res. 2017, 53, 2618-2626. [CrossRef]

14. McCabe, M.F.; Rodell, M.; Alsdorf, D.E.; Miralles, D.G.; Uijlenhoet, R.; Wagner, W.; Lucieer, A.; Houborg, R.; Verhoest, N.E.C.; Franz, T.E.; et al. The future of Earth observation in hydrology. Hydrol. Earth Syst. Sci. 2017, 21, 3879-3914. [CrossRef]

15. Zhang, Y.; Kong, D.; Gan, R.; Chiew, F.H.S.; McVicar, T.R.; Zhang, Q.; Yang, Y. Coupled estimation of $500 \mathrm{~m}$ and 8-day resolution global evapotranspiration and gross primary production in 2002-2017. Remote Sens. Environ. 2019, 222, 165-182. [CrossRef]

16. Frankenberg, C.; Fisher, J.B.; Worden, J.; Badgley, G.; Saatchi, S.S.; Lee, J.-E.; Toon, G.C.; Butz, A.; Jung, M.; Kuze, A.; et al. New global observations of the terrestrial carbon cycle from GOSAT: Patterns of plant fluorescence with gross primary productivity. Geophys. Res. Lett. 2011, 38, L17706. [CrossRef]

17. Shan, N.; Ju, W.; Migliavacca, M.; Martini, D.; Guanter, L.; Chen, J.; Goulas, Y.; Zhang, Y. Modeling canopy conductance and transpiration from solar-induced chlorophyll fluorescence. Agric. For. Meteorol. 2019, 268, 189-201. [CrossRef]

18. McCabe, M.F.; Aragon, B.; Houborg, R.; Mascaro, J. CubeSats in Hydrology: Ultra-High Resolution Insights into Vegetation Dynamics and Terrestrial Evaporation. Water Resour. Res. 2017, 53, 10017-10024. [CrossRef]

19. Manfreda, S.; McCabe, M.; Miller, P.; Lucas, R.; Madrigal, V.P.; Mallinis, G.; Dor, E.B.; Helman, D.; Estes, L.; Ciraolo, G.; et al. On the Use of Unmanned Aerial Systems for Environmental Monitoring. Remote Sens. 2018, 10, 641. [CrossRef]

20. Ershadi, A.; McCabe, M.F.; Evans, J.P.; Wood, E.F. Impact of model structure and parameterization on Penman-Monteith type evaporation models. J. Hydrol. 2015, 525, 521-535. [CrossRef]

21. Pagán, B.R.; Maes, W.H.; Gentine, P.; Martens, B.; Miralles, D.G. Exploring the Potential of Satellite Solar-Induced Fluorescence to Constrain Global Transpiration Estimates. Remote Sens. 2019, 11, 413. [CrossRef]

22. Vanella, D.; Ramírez-Cuesta, J.M.; Intrigliolo, D.S.; Consoli, S. Combining Electrical Resistivity Tomography and Satellite Images for Improving Evapotranspiration Estimates of Citrus Orchards. Remote Sens. 2019, 11, 373.

23. Cheng, J.; Kustas, W.P. Using Very High Resolution Thermal Infrared Imagery for More Accurate Determination of the Impact of Land Cover Differences on Evapotranspiration in an Irrigated Agricultural Area. Remote Sens. 2019, 11, 613. [CrossRef]

24. Guillevic, P.C.; Olioso, A.; Hook, S.J.; Fisher, J.B.; Lagouarde, J.-P.; Vermote, E.F. Impact of the Revisit of Thermal Infrared Remote Sensing Observations on Evapotranspiration Uncertainty-A Sensitivity Study Using AmeriFlux Data. Remote Sens. 2019, 11, 573. [CrossRef]

25. Aragon, B.; Houborg, R.; Tu, K.; Fisher, J.B.; McCabe, M. CubeSats Enable High Spatiotemporal Retrievals of Crop-Water Use for Precision Agriculture. Remote Sens. 2018, 10, 1867. [CrossRef]

26. Martens, B.; de Jeu, R.A.M.; Verhoest, N.E.C.; Schuurmans, H.; Kleijer, J.; Miralles, D.G. Towards Estimating Land Evaporation at Field Scales Using GLEAM. Remote Sens. 2018, 10, 1720. [CrossRef]

27. Trigo, I.F.; Dacamara, C.C.; Viterbo, P.; Roujean, J.-L.; Olesen, F.; Barroso, C.; Camacho-de-Coca, F.; Carrer, D.; Freitas, S.C.; García-Haro, J.; et al. The Satellite Application Facility for Land Surface Analysis. Int. J. Remote Sens. 2011, 32, 2725-2744. [CrossRef]

28. Anderson, M.; Gao, F.; Knipper, K.; Hain, C.; Dulaney, W.; Baldocchi, D.; Eichelmann, E.; Hemes, K.; Yang, Y.; Medellin-Azuara, J.; et al. Field-Scale Assessment of Land and Water Use Change over the California Delta Using Remote Sensing. Remote Sens. 2018, 10, 889. [CrossRef]

29. Sousa, D.; Small, C. Spectral Mixture Analysis as a Unified Framework for the Remote Sensing of Evapotranspiration. Remote Sens. 2018, 10, 1961. [CrossRef]

30. Poon, P.K.; Kinoshita, A.M. Estimating Evapotranspiration in a Post-Fire Environment Using Remote Sensing and Machine Learning. Remote Sens. 2018, 10, 1728. [CrossRef] 
31. Talsma, C.J.; Good, S.P.; Miralles, D.G.; Fisher, J.B.; Martens, B.; Jimenez, C.; Purdy, A.J. Sensitivity of Evapotranspiration Components in Remote Sensing-Based Models. Remote Sens. 2018, 10, 1601. [CrossRef]

32. Moyano, M.C.; Garcia, M.; Palacios-Orueta, A.; Tornos, L.; Fisher, J.B.; Fernández, N.; Recuero, L.; Juana, L. Vegetation Water Use Based on a Thermal and Optical Remote Sensing Model in the Mediterranean Region of Doñana. Remote Sens. 2018, 10, 1105. [CrossRef]

33. Kumar, S.; Holmes, T.; Mocko, D.M.; Wang, S.; Peters-Lidard, C. Attribution of Flux Partitioning Variations between Land Surface Models over the Continental U.S. Remote Sens. 2018, 10, 751. [CrossRef]

34. Rasul, G.; Sharma, B. The nexus approach to water-energy-food security: An option for adaptation to climate change. Clim. Policy 2016, 16, 682-702. [CrossRef]

35. Hanjra, M.A.; Qureshi, M.E. Global water crisis and future food security in an era of climate change. Food Policy 2010, 35, 365-377. [CrossRef]

36. Miralles, D.G.; Gentine, P.; Seneviratne, S.I.; Teuling, A.J. Land-Atmos. Land-atmospheric feedbacks during droughts and heatwaves: State of the science and current challenges. Ann. N. Y. Acad. Sci. 2019, 1436, 19-35. [CrossRef] [PubMed]

37. Bastiaanssen, W.G.M.; Noordman, E.J.M.; Pelgrum, H.; Davids, G.; Thoreson, B.P.; Allen, R.G. SEBAL Model with Remotely Sensed Data to Improve Water-Resources Management under Actual Field Conditions. J. Irrig. Drain. Eng. 2005, 131, 85-93. [CrossRef]

38. Malenovský, Z.; Rott, H.; Cihlar, J.; Schaepman, M.E.; García-Santos, G.; Fernandes, R.; Berger, M. Sentinels for science: Potential of Sentinel-1, -2 , and -3 missions for scientific observations of ocean, cryosphere, and land. Remote Sens. Environ. 2012, 120, 91-101. [CrossRef]

39. Houborg, R.; McCabe, M.F. Daily Retrieval of NDVI and LAI at $3 \mathrm{~m}$ Resolution via the Fusion of CubeSat, Landsat, and MODIS Data. Remote Sens. 2018, 10, 890. [CrossRef]

40. Hulley, G.; Hook, S.; Fisher, J.; Lee, C. ECOSTRESS, A NASA Earth-Ventures Instrument for studying links between the water cycle and plant health over the diurnal cycle. In Proceedings of the International Geoscience and Remote Sensing Symposium (IGARSS), Fort Worth, TX, USA, 23-28 July 2017.

41. Talsma, C.J.; Good, S.P.; Jimenez, C.; Martens, B.; Fisher, J.B.; Miralles, D.G.; McCabe, M.F.; Purdy, A.J. Partitioning of evapotranspiration in remote sensing-based models. Agric. For. Meteorol. 2018, 260-261, 131-143. [CrossRef]

42. Guan, K.; Wu, J.; Kimball, J.S.; Anderson, M.C.; Frolking, S.; Li, B.; Hain, C.R.; Lobell, D.B. The shared and unique values of optical, fluorescence, thermal and microwave satellite data for estimating large-scale crop yields. Remote Sens. Environ. 2017, 199, 333-349. [CrossRef]

43. Purdy, A.J.; Fisher, J.B.; Goulden, M.L.; Colliander, A.; Halverson, G.; Tu, K.; Famiglietti, J.S. SMAP soil moisture improves global evapotranspiration. Remote Sens. Environ. 2018, 219, 1-14. [CrossRef]

44. Holmes, T.R.H.; Hain, C.R.; Crow, W.T.; Anderson, M.C.; Kustas, W.P. Microwave implementation of two-source energy balance approach for estimating evapotranspiration. Hydrol. Earth Syst. Sci. 2018, 22, 1351-1369. [CrossRef] [PubMed]

45. Qiu, B.; Xue, Y.; Fisher, J.B.; Guo, W.; Berry, J.A.; Zhang, Y. Satellite Chlorophyll Fluorescence and Soil Moisture Observations Lead to Advances in the Predictive Understanding of Global Terrestrial Coupled Carbon-Water Cycles. Glob. Biogeochem. Cycles 2018, 32, 360-375. [CrossRef]

46. Alemohammad, S.H.; Fang, B.; Konings, A.G.; Aires, F.; Green, J.K.; Kolassa, J.; Miralles, D.; Prigent, C.; Gentine, P. Water, Energy, and Carbon with Artificial Neural Networks (WECANN): A statistically based estimate of global surface turbulent fluxes and gross primary productivity using solar-induced fluorescence. Biogeosciences 2017, 14, 4101-4124. [CrossRef] [PubMed]

47. Shen, C.; Laloy, E.; Elshorbagy, A.; Albert, A.; Bales, J.; Chang, F.J.; Ganguly, S.; Hsu, K.L.; Kifer, D.; Fang, Z.; et al. HESS Opinions: Incubating deep-learning-powered hydrologic science advances as a community. Hydrol. Earth Syst. Sci. 2018, 22, 5639-5656. [CrossRef]

48. Bodesheim, P.; Jung, M.; Gans, F.; Mahecha, M.D.; Reichstein, M. Upscaled diurnal cycles of land-atmosphere fluxes: A new global half-hourly data product. Earth Syst. Sci. Data 2018, 10, 1327-1365. [CrossRef]

(C) 2019 by the authors. Licensee MDPI, Basel, Switzerland. This article is an open access article distributed under the terms and conditions of the Creative Commons Attribution (CC BY) license (http://creativecommons.org/licenses/by/4.0/). 